\title{
Avaliação da eficiência do extrato aquoso de mandioca sobre Meloidogyne incognita in vitro
}



Fábio Mazzonetto

Vera Lúcia Monelli Sossai

Raphael Benassatto ${ }^{3}$

Valéria Peruca de Melo 4

Luiz Carlos Pizetta ${ }^{5}$

\section{Resumo}

Com o objetivo de avaliar o efeito do extrato aquoso de mandioca sobre a eclosão e inativação de juvenis de Meloidogyne incognita in vitro, foi conduzido um experimento no Laboratório de Fitotecnia da Universidade Camilo Castelo Branco, a uma temperatura de $25 \pm 2^{\circ} \mathrm{C}$, umidade relativa de $70 \pm 10 \%$. Na obtenção do extrato aquoso, foram utilizados aproximadamente $5 \mathrm{~kg}$ de mandioca que foi descascada, lavada, picada e levada a um liquidificador industrial para a trituração, sendo em seguida coada em um béquer e levada à geladeira por 24 horas. 0 delineamento experimental utilizado foi inteiramente ao acaso (DIC), com cinco repetições e sete concentrações do extrato aquoso de mandioca $(0,5,10,15,20,25$ e $30 \%)$. Os ovos em solução do extrato foram incubados a $26^{\circ} \mathrm{C}$ em estufa, durante 16 dias, obtendo-se os dados de eclosão, que foram expressos em porcentagem e transformados em log $(x+1)$. Nas condições em que este experimento foi conduzido, e com base nas análises efetuadas, pôde-se concluir que o extrato de mandioca, nas concentrações acima de $10 \%$, proporcionou uma eclosão nula de juvenis, constatando uma eficácia de $100 \%$ deste produto ao nematoide, sendo uma alternativa eficaz no controle de fitonematoides do gênero Meloidogyne.

Palavras-chave: Controle alternativo. Extratos vegetais. Fitonematoides. Manihot esculenta.

\section{Introdução}

Os ataques de fitonematoides resultam em danos - de leves a severos - em diversas culturas agrícolas, dependendo da espécie de nematoide, do grau de infestação do solo e das condições ambientais. De maneira geral, os nematoides parasitas de plantas são responsáveis pela redução de cerca de $11 \%$ da produção agrícola mundial (AGRIOS, 2005), o que corresponde a uma redução de milhões de toneladas por ano. Essas perdas causadas pelos nematoides nas diversas culturas, em termos mundiais, representam até 100 bilhões de dólares (TIHOHOD, 1997).

\footnotetext{
1 Universidade Camilo Castelo Branco - UNICASTELO, professor titular. Descalvado, São Paulo, Brasil. coord.agronomia.des@unicastelo.br. (19) 3593-8500. Avenida Hilário da Silva Passos, 950, Bairro Parque Universitário, Descalvado, São Paulo, CEP $13690-000$.

2 Universidade Camilo Castelo Branco - UNICASTELO, professor assistente. Descalvado, São Paulo, Brasil. veramonelli@gmail.com. (19) 3593-8500. Avenida Hilário da Silva Passos, 950, Bairro Parque Universitário, Descalvado, São Paulo, CEP 13690-000.

3 Universidade Camilo Castelo Branco - UNICASTELO, aluno de graduação. Descalvado, São Paulo, Brasil. famazzonetto@hotmail. com. (19) 3593-8500. Avenida Hilário da Silva Passos, 950, Bairro Parque Universitário, Descalvado, São Paulo, CEP 13690-000.

$4 \quad$ Universidade Camilo Castelo Branco - UNICASTELO, professor auxiliar. Descalvado, São Paulo, Brasil. vpmelo@bol.com.br. (19) 3593-8500. Avenida Hilário da Silva Passos, 950, Bairro Parque Universitário, Descalvado, São Paulo, CEP 13690-000.

$5 \quad$ Universidade Camilo Castelo Branco - UNICASTELO, professor assistente. Descalvado, São Paulo, Brasil. luizcarlospizetta@bol.
} com.br. (19) 3593-8500. Avenida Hilário da Silva Passos, 950, Bairro Parque Universitário, Descalvado, São Paulo, CEP 13690-000. 
Meloidogyne incognita e Meloidogyne javanica são os nematoides que causam mais prejuízos para a agricultura brasileira. São patogênicos a diferentes espécies de importância econômica e estão amplamente disseminados nas áreas agricultáveis do Brasil (FERRAZ; SANTOS, 1984).

De acordo com Tihohod (1997), inúmeros graus de sintomas são apresentados pela espécie Meloidogyne, como: presença de galhas nas raízes, clorose, redução e deformação do sistema radicular, decréscimo da eficiência das raízes em absorver e translocar água e nutrientes, além de menor crescimento da parte aérea. Pela sua alta capacidade reprodutiva, ampla gama de hospedeiros e por apresentar fácil adaptação a diferentes condições de ecossistema, o controle de Meloidogyne spp. torna-se bastante dificultado (FERRAZ, 1985). Porém, depois de sua introdução na área, devem ser realizados métodos de controle, a fim de reduzir populações a níveis toleráveis (CAMPOS et al., 1998).

Vários métodos de controle têm sido pesquisados na tentativa de reduzir a população de nematoide abaixo do nível econômico de dano e de proporcionar o controle satisfatório desse fitopatógeno (SIKORA, FERNÁNDEZ, 2004). O uso de nematicidas é uma das táticas de manejo, porém, além das implicações de ordem econômica, as de ordem ecotoxicológicas são frequentemente lembradas, visto que tais produtos são de alta toxicidade e, consequentemente, são tidos como potencialmente danosos ao meio ambiente (CORBANI, 2008). Nos últimos anos, têm se direcionado diversas pesquisas para a descoberta de substâncias biologicamente ativas, que possam ser introduzidas como produto natural no manejo integrado de pragas e doenças, a fim de reduzir o efeito negativo ao ambiente (CASTRO, 1989).

Segundo Quarles (1992), extratos vegetais apresentam algumas vantagens em relação a pesticidas sintéticos no controle de fitopatógenos, dentre elas: são menos concentrados e, consequentemente, menos tóxicos; têm possibilidades de gerar novos compostos que os patógenos ainda não foram capazes de inativar; são biodegradados rapidamente; são derivados de recursos renováveis e possuem um amplo modo de ação.

Plantas que apresentam efeitos antagônicos a nematoides têm se mostrado promissoras para esse fim, podendo ser utilizadas em rotação de culturas, plantio intercalar ou aplicadas como tortas ou extratos vegetais (OLIVEIRA et al., 2005). Alguns extratos obtidos de diversas espécies de vegetais têm apresentado substâncias com efeitos nematicidas (KHURMA, SINGII, 1997; ABID et al., 1997; DIAS et al., 2000; COSTA et al., 2001; CORBANI et al., 2010). Os extratos naturais podem se tornar um dos métodos de controle mais promissores de patógenos do solo, como, por exemplo, os nematoides, podendo substituir os produtos químicos e se tornarem uma medida alternativa para pequenas áreas (SCRAMIN et al., 1987).

Dessa forma, objetivou-se avaliar o efeito de extrato aquoso da mandioca (Manihot esculenta Crantz) sobre a eclosão de juvenis de $M$. incognita in vitro.

\section{Material e métodos}

O experimento foi conduzido no Laboratório de Fitotecnia da Universidade Camilo Castelo Branco, campus Descalvado - SP, no período de janeiro de 2013 a janeiro de 2014.

\section{Inoculação de Meloidogyne incognita em mudas de Jiló (Solanum gilo)}

Foram plantadas mudas de Jiló (S. gilo) em vasos de barro de $15 \mathrm{~L}$, as quais receberam adubação com esterco de curral curtido e adubo químico na formulação 04-14-08, conforme recomenda- 
ções para a cultura, além de regas diárias e tratos de capina manual. Os nematoides da espécie $M$. incognita foram inoculados nesses vasos para sua multiplicação.

\section{Coleta dos ovos de Meloidogyne incógnita}

Os ovos de M. incognita foram extraídos conforme metodologia adaptada por Boneti e Ferraz (1981). Foram coletadas as plantas de Jiló com todas as raízes. As raízes infestadas foram lavadas cuidadosamente em água corrente e, posteriormente, cortadas em fragmentos de aproximadamente $2 \mathrm{~cm}$ e trituradas em liquidificador a baixa velocidade, em uma solução contendo $250 \mathrm{~mL}$ de água destilada e hipoclorito de sódio a uma concentração de $0,5 \%$, durante 20 segundos. A suspensão resultante foi passada por duas peneiras granulométricas sobrepostas, sendo a superior de 100 'mesh' $(0,074 \mathrm{~mm}$ de abertura de malha) e a inferior de 500 'mesh' $(0,025 \mathrm{~mm}$ de abertura de malha). A suspensão retida na última peneira foi lavada com água corrente e recolhida em um béquer para realizar a contagem do número de ovos, com o auxílio de câmara de Peters, em microscópio estereoscópio.

\section{Preparo do extrato aquoso de mandioca}

O extrato aquoso foi obtido utilizando-se aproximadamente $5 \mathrm{~kg}$ de mandioca de mesa (Manihot esculenta Crantz), que foram descascadas, lavadas, picadas e levadas a um liquidificador industrial para a trituração, sendo em seguida coada em um béquer e levada à geladeira por 24 horas para decantação do amido e dos resíduos sólidos.

As concentrações escolhidas do extrato aquoso de mandioca e utilizadas no experimento foram: T1(testemunha - 0\%, T2 (5\% do extrato), T3 (10\% do extrato), T4 (15\% do extrato), T5 (20\% do extrato), T6 (25\% do extrato) e T7 (30\% do extrato).

\section{Montagem do bioensaio para verificação da inibição na eclosão de juvenis de Meloidogyne incognita}

Em placas de Petri de $5 \mathrm{~cm}$ de diâmetro, foram colocados, separadamente, $5 \mathrm{~mL}$ do extrato, em concentração dupla, de modo a proporcionar as concentrações finais mencionadas para cada tratamento, e $5 \mathrm{~mL}$ de suspensão aquosa, contendo aproximadamente 1700 ovos de M. incognita. Água destilada foi utilizada no tratamento da testemunha. Foram feitas 5 repetições para cada tratamento.

As placas de Petri de cada tratamento foram distribuídas de acordo com o delineamento inteiramente ao acaso (DIC) e incubadas em estufas tipo B.O.D. a temperatura constante de $28^{\circ} \mathrm{C}$, durante 16 dias. Decorrido esse tempo, foi coletado $1 \mathrm{~mL}$ para contagem do número de juvenis eclodidos e de ovos remanescentes, com o auxílio do microscópio estereoscópio, sendo calculada a porcentagem de eclosão de juvenis de acordo com a seguinte fórmula:

$\%$ de eclosão $=\left[n^{0}\right.$ de juvenis $/\left(n^{\circ}\right.$ de juvenis $+n^{\circ}$ de ovos $\left.)\right] \times 100$ (1)

Os dados obtidos dos testes de eclosão de ovos referentes ao efeito das sete concentrações do extrato aquoso da mandioca foram expressos em porcentagem, transformados em log $(x+1)$ e submetidos à análise variância da regressão (ANOVA) ao nível de $1 \%$ de probabilidade, com o auxílio do software ASSISTAT Versão 7.6 beta (SILVA, 2013). 


\section{Resultados e discussão}

Os resultados obtidos quanto à porcentagem de eclosão de juvenis de $M$. incognita, nas diferentes concentrações do extrato aquoso de mandioca, encontram-se na Tabela 1 e Figura 1.

Tabela 1. Porcentagem de eclosão de juvenis e eficácia do extrato aquoso de mandioca em diferentes concentrações (Descalvado, SP).

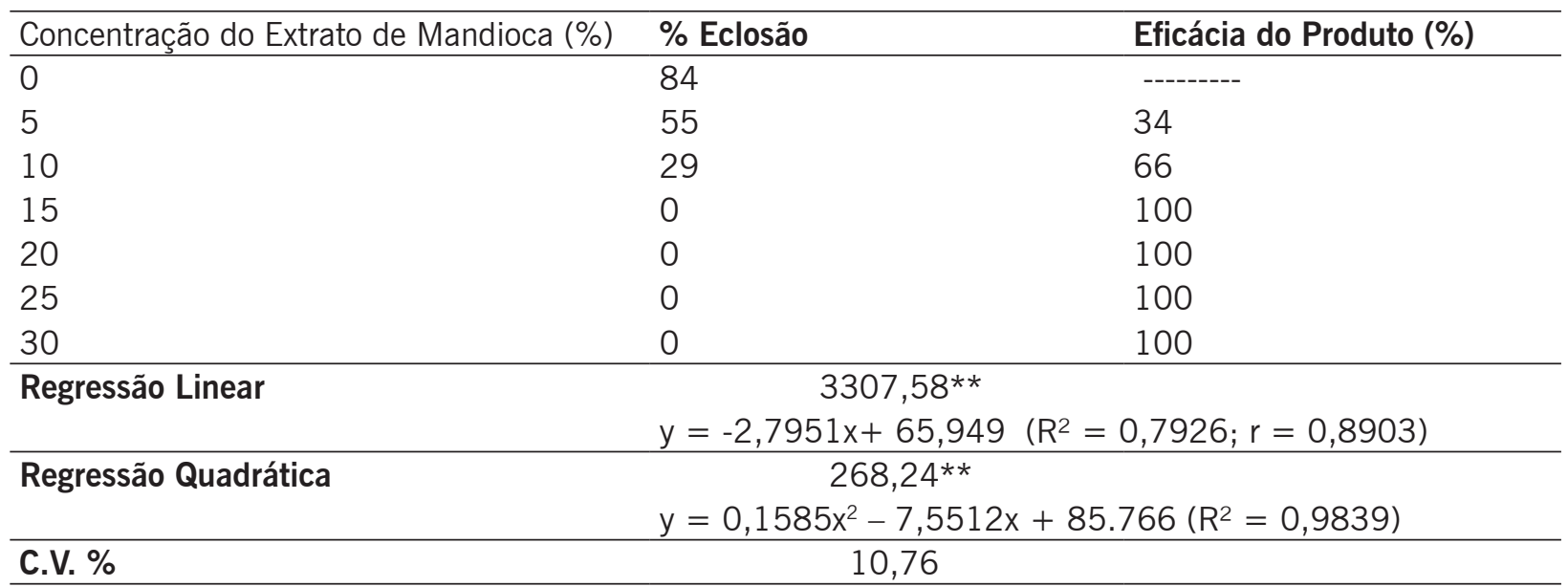

**Significativo pelo teste $\mathrm{F}(\mathrm{P} \leq 0,01)$.

Fonte: Elaboração dos autores.

Pode-se verificar nesses dados que a eclosão de juvenis foi maior na testemunha, na qual não houve utilização do extrato de mandioca, resultando no valor máximo de eclosão de juvenis (84\%). As concentrações de 5 e $10 \%$ do extrato de mandioca proporcionaram uma menor porcentagem de eclosão (55\% e 29\%, respectivamente), quando comparados com a testemunha. Em termos de eficácia do extrato, as concentrações acima de 10\% (15 a 30\%) mostraram-se muito eficientes no controle do nematoide, já que a eclosão foi nula, com eficácia de $100 \%$ do produto.

Nos resultados da análise de variância da regressão (Tabela 1), observa-se que o modelo quadrático foi o que melhor se ajustou, demonstrando o maior coeficiente de determinação $R^{2}=0,9839$, que pode ser considerado alto em se tratando de um fenômeno biológico, e expressa que 98,39\% da variação na porcentagem de eclosão de ovos de nematoide $M$. incognita são explicados pela variação das doses do extrato aquoso de mandioca. Na Figura 1, pode-se observar tal comportamento.

O efeito linear com significância de $1 \%$ apresentado na Tabela 1 , com equação y $=-2,7951 x$ $+65,949$, estima que, para cada aumento de $1 \%$ do extrato de mandioca, ocorre um decréscimo de $2,7951 \%$ na eclosão de ovos. Com um valor de correlação $r$ de 0,8903 , pode-se dizer que acréscimos nas doses do extrato de mandioca correspondem a decréscimos na porcentagem de eclosão.

Tornou-se visível que, com o aumento das concentrações do extrato de mandioca e, consequentemente, o aumento das concentrações das substâncias com ação nematicida, ocorre um decréscimo da porcentagem de eclosão em decorrência da ação de toxicidade sobre a espécie de $M$. incognita. 


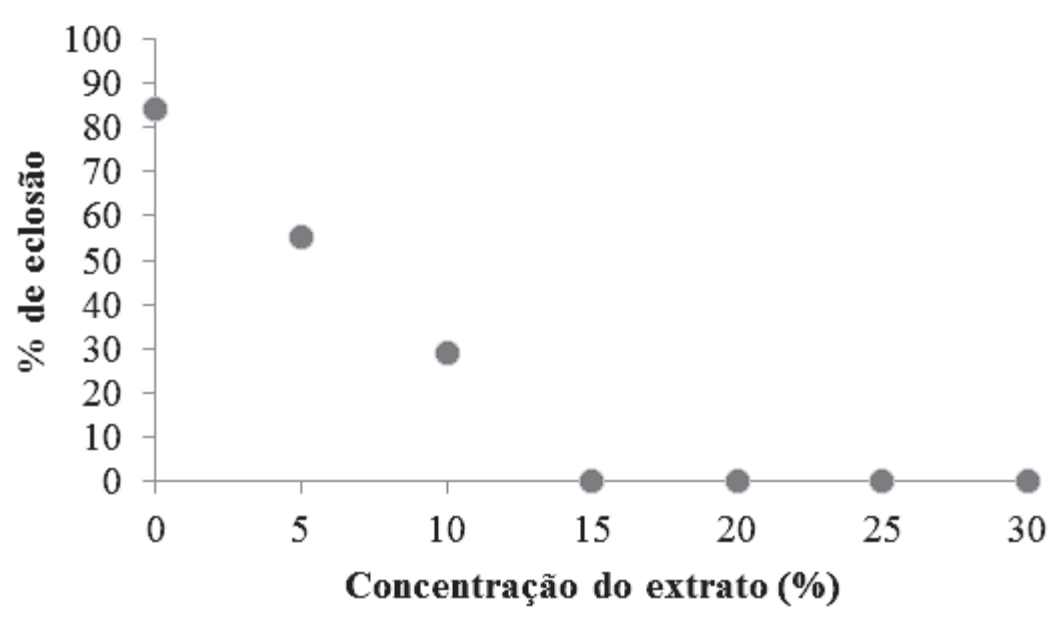

Figura 1. Porcentagem de eclosão de juvenis em função das diferentes concentrações do extrato aquoso de mandioca (Descalvado, SP).

Fonte: Elaboração dos autores.

Segundo Ponte et al. (1995), o resíduo industrial do processamento da mandioca, conhecido como manipueira, há tempos tem se revelado como uma opção no controle de nematoides fitoparasitos. Entretanto, sua utilização na prática ainda não tem sido frequente. A manipueira possui diversas substâncias que se transformam em ácido cianídrico e cianetos, apresentando ação nematicida, como comprovado por Ponte (2001) e confirmado neste experimento.

Estudos realizados por Ponte e Franco (1983) em cultivo de cenoura com ataque de Meloidogyne spp. comprovaram o potencial nematicida do extrato de mandioca, pois com o seu uso, na dose de $100 \mathrm{~mL} / 6 \mathrm{~L}$ de solo, a percentagem de plantas atacadas foi igual a zero. Em outra pesquisa, Sena e Ponte (1982) constataram elevado índice de controle de Meloidogyne spp. em canteiros de cenoura tratados com extrato de mandioca $\left(1 \mathrm{~L} / \mathrm{m}^{2}\right)$, com produção $100 \%$ superior à obtida nos canteiros não tratados.

Franco et al. (1990) testaram, em tratamento de solo naturalmente infestado por Meloidogyne, o extrato de manipueira diluída em água (1:1), nas doses 4,6 e $8 \mathrm{~L} / \mathrm{m}^{2}$. Os autores concluíram que a menor dose foi suficiente para promover um eficiente controle dos nematoides.

Baldin et al. (2012), avaliando o efeito de diversos extratos aquosos no desenvolvimento de plantas de cenoura cultivadas em solo infestado com ovos e eventuais juvenis infectantes de Meloidogyne incognita, observaram que as raízes tratadas com extrato à base de mandioca se destacaram positivamente, com maiores médias de peso fresco total (raiz + parte aérea) e menor número de raízes secundárias.

\section{Conclusões}

Pelos resultados obtidos, pode-se concluir que:

- os extratos de mandioca nas concentrações acima de 10\% proporcionaram uma eclosão nula de juvenis, constatando uma eficácia de $100 \%$ desse produto ao nematoide $M$. incognita.

- O extrato de mandioca é uma alternativa eficaz no controle de fitonematoides do gênero Meloidogyne. 


\title{
Efficiency evaluation on aqueous extract of manioc on Meloidogyne incognita in vitro
}

\begin{abstract}
With the objective of evaluating the effect of aqueous extract of manioc on the hatching and inactivation of juveniles of Meloidogyne incognita in vitro, an experiment was conducted in the Laboratory of Agronomy at University Camilo Castelo Branco at $25 \pm 2^{\circ} \mathrm{C}$ temperature, and $70 \pm 10 \%$ relative humidity. In order to obtain the aqueous extract approximately $5 \mathrm{~kg}$ of cassava were used. This cassava was peeled, washed, chopped and crushed in an industrial blender, being then strained to a becher and brought to refrigerator for 24 hours. The experimental design was completely randomized (IHD), with five repetitions and seven concentrations of cassava's aqueous extract $(0,5,10,15,20$, 25 and $30 \%$ ). The eggs in extract solution were incubated at $26^{\circ} \mathrm{C}$ in the incubator during 16 days, obtaining data from hatching that were expressed in percentage and converted to $\log (x+1)$. Under the conditions in which this experiment was conducted, and based on the analyzes performed, it can be concluded that the extract of cassava in concentrations above $10 \%$ produced a null hatching of juveniles, observing an efficiency of $100 \%$ of this product to root-knot nematode, being an effective alternative in the control of plant parasitic nematodes of Meloidogyne genus.
\end{abstract}

Keywords: Alternative control. Vegetal extracts. Nematodes. Manihot esculenta.

\section{Referências}

ABID, M.; CHOUDHARY, M. I.; MAQBOOL, M. A; RAHMAN, A. U. Preliminary screening of some plants for their nematicidal activity against Meloidogyne javanica. Nematologia Mediterranea, Bari, v.25, p.155-157, 1997.

AGRIOS, G. N. Plant Pathology. 5.ed. Academic Press, USA. 2005. 922 pp.

BALDIN, E. L. L.; WILCKEN, S. R. S.; PANNUTI, L. E. R.; SCHLICK-SOUZA, E. C.; VANZEI, F. P. Uso de extratos vegetais, manipueira e nematicida no controle do nematoide das galhas em cenoura. Summa Phytopathologica, Botucatu, v.38, p.36-41, 2012.

BONETI, J. I. S.; FERRAZ, S. Modificação do método de Hussey \& Barker para extração de ovos de Meloidogyne exigua em raízes de cafeeiro. Fitopatologia Brasileira, Brasília, v.6 (suplemento), p. 553, 1981. (Resumo)

CAMPOS, V. P.; SOUZA, J. T.; SOUZA, R. M. Controle de fitonematóides por meio de bactérias. Revisão Anual de Patologia de Plantas, Passo Fundo, p. 285-327, 1998.

CORBANI, R. Z. Estudo do extrato pirolenhoso Biopirol@ no manejo de nematoides em canade-açúcar, olerícolas e citros em diferentes ambientes. 2008. 53f. Tese (Doutorado em Agronomia) - Faculdade de Ciências Agrárias e Veterinárias, Universidade Estadual Paulista, Jaboticabal.

CORBANI, R. Z.; ALTOÉ, J.; MAZZONETTO, F.; DALRI, A. B.; SOSSAI, V. L. M.; PIZETTA, L. C. Efeito 
de óleos essenciais sobre a eclosão de juvenis de Meloidogyne javanica in vitro. Revista Agrarian, Dourados, v.3, n.10, p.194-199, 2010.

CASTRO, A.G. Defensivos agrícolas como um fator ecológico. Jaguariuna: EMBRAPA - CNPDA (Documento, 6), 1989. 20p.

COSTA, M. J. N.; CAMPOS, V. P.; OLIVEIRA, D. F.; PFENNING, L. H. Toxicidade de extratos vegetais e de estercos a Meloidogyne incognita. Summa Phytopathologica, Botucatu, v. 27, p. 245-250, 2001.

DIAS, C.R.; SCHWAN, A.V.; EZEQUIEL, D.P.; SARMENTO, M.C.; FERRAZ, S. Efeito de extratos aquosos de plantas medicinais na sobrevivência de juvenis de Meloidogyne incognita. Nematologia Brasileira, Piracicaba, v. 24, p. 203-210, 2000.

FERRAZ, S.; SANTOS, J.M. Os problemas com nematóides na cultura da cenoura e da mandioquinha-salsa. Informe Agropecuário, Belo Horizonte, v.10, p. 52-60, 1984.

FERRAZ, S. Summary report on the current status, progress and needs for Meloidogyne research in Brazil (Region III). In: SASSER, J.N.; CARTER, C.C. (Ed.). An advanced treatise on Meloidogyne. Volume I: Biology and control. Raleigh: North Caroline State University Graphics, p. 351-352. 1985.

FRANCO, A.; PONTE, J. J.; SILVA, R. S.; SANTOS, F.A.M. Dosagem de manipueira para tratamento de solo infestado por Meloidogyne. Nematologia Brasileira, Piracicaba, v.14, p. 25-32, 1990.

KHURMA, U. R.; SINGII, A. Nematicidal potential of seed extracts: in vitro effects on juvenile mortality and egg hatch of Meloidogyne incognita and M. javanica. Nematologia Mediterranea, Bari, v. 25, p. 49-54, 1997.

OLIVEIRA, F. S.; ROCHA, M. R.; REIS, A. J. S.; MACHADO, V. O. F.; SOARES, R. A. B. Efeito de produtos químicos e naturais sobre a população de nematoide Pratylenchus brachyurus na cultura da cana-de-açúcar. Pesquisa Agropecuária Tropical, Goiânia, v. 35, p.171-178, 2005.

PONTE, J. J. Uso da manipueira como insumo agrícola: Defensivo e Fertilizante. In: CEREDA, M. P. Manejo, uso e tratamento de subprodutos da industrialização da mandioca. São Paulo: Fundação Cargill, 2001. p.80-95.

PONTE, J. J.; FRANCO, A. Manipueira um nematicida não convencional de comprovada potencialidade. Nematologia Brasileira, Piracicaba, v.7, p.21-25, 1983.

PONTE, J. J.; FRANCO, A.; SILVEIRA-FILHO, J.; SANTOS, F.A.M. Dosagem de manipueira para tratamento de linhas de cultivo em solo infestado de Meloidogyne. Nematologia Brasileira, Piracicaba, v.19, p.81-85, 1995.

QUARLES, W. Botanical pesticides from Chenopodium. The IPM Practitioner, v. 14, n. 2, p. 1-11, 1992.

SCRAMIN, S.; SILVA, H. P.; FERNANDES, L. M. S., YHAN, C. A. Biological evaluation of 14 extracts of plant species on Meloidogyne incognita race I. Nematologia Brasileira, Piracicaba, v. 11, p. 89102, 1987. 
SENA, E. S.; PONTE, J. J. A manipueira no controle da meloidoginose da cenoura. Nematologia Brasileira, Piracicaba, v.6, p.95-98, 1982.

SIKORA, R. A.; FERNÁNDEZ, E. Nematode parasites of vegetables. In: CHEN, Z.; CHEN, S.; DICKSON, D. W. (Ed.). Nematology - Advances and Perspectives. Volume II: Nematode Management and Utilization. Beijing \& Wallingford, Tsinghua University Press \& CABI Publishing, p. 319-392, 2004.

SILVA, F.A.S. Software ASSISTAT, versão 7.6 beta Homepage http://www.assistat.com. DEAG-CTRNUFCG, 2013.

TIHOHOD, D. Guia prático para a identificação de fitonematóides. Jaboticabal: FUNEP, 1997. 67p.

\section{Histórico editorial}

Submetido em: 13/05/2014

Aceito em: 23/01/2015 